\title{
JS-7
}

20日 (水) 名古屋能楽堂

\section{Prognostic variables and nomograms for renal cell carcinoma}

\section{AUA Secretary / Loyola University Medical Center, Maywood, USA}

Robert C. Flanigan

The term renal cell carcinoma (RCC) is used to describe a heterogeneous group of tumors that vary histologically, genetically and molecularly. Risk factors predicting RCC behavior, in addition to histologic subtype, include tumor size, tumor stage, tumor grade, patient age, mode of presentation, and other laboratory indices. It is now possible to use nomograms which incorporate these various features in order to help define individual patent prognosis and direct optimal therapy.

\section{JS-8}

20日 (水) 名古屋能楽堂

\section{AUA policy regarding PSA}

AUA President / The Chief of Urology, Sisters of Charity Hospital, USA

Datta G. Wagle

Prostate Cancer is the most common non-skin cancer in the United States. Prior to the emergence of PSA testing in the United States only $68 \%$ of newly diagnosed men had cancer localized to the prostate; $21 \%$ had metastatic disease ; and $48 \%$ of cancers were clinical stages T1A to T1C. After the emergence of PSA testing in the United States, deaths from prostate cancer in the United States have decreased by $40 \%$ over the past decade-a greater decline than any other cancer in the United States. This presentation will focus on the impact that PSA testing has had on reducing the number of deaths in the Unites States from prostate cancer as well as the need for early detection, and the American Urological Association's clinical guidelines on PSA. 